\title{
In Vivo Analysis of the Potency of Silicone Oil Microdroplets as Immunological Adjuvants in Protein Formulations
}

\author{
CARLY FLEAGLE CHISHOLM, ${ }^{1}$ BAO HAN NGUYEN, ${ }^{1}$ KAITLIN R. SOUCIE, ${ }^{1}$ RAUL M. TORRES, ${ }^{2}$ JOHN F. CARPENTER, ${ }^{3}$ \\ THEODORE W. RANDOLPH ${ }^{1}$ \\ ${ }^{1}$ Department of Chemical and Biological Engineering, University of Colorado, Boulder, Colorado 80309 \\ ${ }^{2}$ Department of Immunology \& Microbiology, University of Colorado School of Medicine, Aurora, Colorado 80045 \\ ${ }^{3}$ Department of Pharmaceutical Sciences, University of Colorado Anschutz Medical Campus, Aurora, Colorado 80045
}

Received 12 May 2015; revised 19 June 2015; accepted 22 June 2015

Published online 17 July 2015 in Wiley Online Library (wileyonlinelibrary.com). DOI 10.1002/jps.24573

\begin{abstract}
Subvisible particles in a therapeutic protein product may act as adjuvants to promote unwanted immune responses against the protein. Silicone oil is used as a lubricant in prefilled syringes, and microdroplets of silicone oil are often detected in protein formulations expelled from prefilled syringes. In order to test the adjuvant potency of silicone oil microdroplets, antibody responses in mice to subcutaneous injections of formulations of ovalbumin (OVA) that contained silicone oil microdroplets were measured. These responses were compared against responses to oil-free OVA formulations and to OVA formulations that contained microparticulate aluminum hydroxide ("alum"), the common vaccine adjuvant. When administered with high concentrations of silicone oil microdroplets, OVA formulations elicited strong anti-OVA $\operatorname{lgG} 1$ and $\operatorname{lgG} 2 \mathrm{a}$ antibody responses. These responses were equivalent to those observed when alum microparticles were added to OVA formulations, suggesting that silicone oil can act as a potent adjuvant. However, when OVA formulations were prepared with lower levels of silicone oil that had been obtained directly from commercial siliconized syringes, the anti-OVA antibody response was not enhanced significantly compared with responses against OVA alone. ๑) 2015 Wiley Periodicals, Inc. and the American Pharmacists Association J Pharm Sci 104:3681-3690, 2015
\end{abstract}

Keywords: protein formulation; protein structure; immune response; immunology; protein aggregation; subvisible particles; particle size; prefilled syringes; silicone oil; adjuvant effect

\section{INTRODUCTION}

Therapeutic proteins play significant roles in treatment of a broad range of human diseases and conditions because of their high specificity and functionality. ${ }^{1}$ However, therapeutic protein products may cause unwanted immune responses in patients, leading to production of anti-drug antibodies (ADAs). ${ }^{2}$ ADAs may bind to therapeutic protein molecules and reduce their therapeutic efficacy by neutralizing their activity and/or increasing their rates of clearance. Additionally, ADAs may be cross-reactive and inactivate the drug's endogenous counterpart, potentially leading to severe side effects. ${ }^{3}$

Endocrine or metabolic disorders in which deficiencies in specific proteins exist can be treated using therapeutic protein products. ${ }^{1}$ Administration of proteins for replacement therapies often produces ADAs, at least in part, because the immune system may recognize the therapeutic proteins as foreign. ${ }^{4}$ For example, in hemophilia A patients whose factor VIII gene has been deleted or modified, administration of factor VIII can generate ADAs. ${ }^{5}$ ADAs can also be produced against recombinant therapeutic protein products, even when the proteins are engineered to be identical to their endogenous counterparts and thus would be expected to be seen by the immune system as "self." 2 For instance, recombinant human erythropoietin can induce ADAs that are cross-reactive against endogenous erythropoietin and induce pure red cell aplasia in patients. ${ }^{6}$

Correspondence to: Theodore W. Randolph (Telephone: +303-492-4776; Fax: +303-492-8425; E-mail: Theodore.randolph@colorado.edu)

Journal of Pharmaceutical Sciences, Vol. 104, 3681-3690 (2015)

(C) 2015 Wiley Periodicals, Inc. and the American Pharmacists Association
The causes for immunogenicity of therapeutic protein products are not completely understood. Many factors could influence the production of ADAs, including impurities, non-human origin, protein structure, protein aggregates, particulate contaminants, dosing regimen, route of administration, genetic background of the patient, and associated disease. ${ }^{7}$ Subvisible particles composed of protein and/or particulate contaminants may be a particularly important factor in unwanted immunogenicity.

Early studies that investigated the effect of proteinaceous particles on immunogenicity found that rabbits injected with the supernatant of an ultracentrifuged human gamma globulin formulation did not produce detectable ADAs, whereas rabbits that were administered with the proteinaceous particles that sedimented in the ultracentrifuge produced large amounts of ADAs after injection. ${ }^{8}$ Likewise, aggregates of human gamma globulin were more immunogenic than monomers in rats, guinea pigs, mice, and dogs. ${ }^{9-11}$ Weksler et al. ${ }^{12}$ reported that human patients could maintain tolerance to injections of horse anti-human lymphocyte globulin that had been ultracentrifuged to remove particulates. In more recent studies, protein aggregates formed from agitation or freeze-thawing of formulations of recombinant human growth hormone were associated with increased antibody responses when the formulations were administered to mice. ${ }^{13}$ In another study, formulations that contained proteinaceous particles created by stirring were found to be immunogenic and enhanced the in vitro innate immune response and T-cell response in human peripheral blood mononuclear cells. ${ }^{14}$ Enhanced expression of co-stimulatory signals from dendritic cells were associated with increased subvisible 
particle concentrations, ${ }^{15}$ and even minute amounts of subvisible proteinaceous particles resulted in increased expression of co-stimulatory signals from dendritic cells. ${ }^{16}$

In addition to proteinaceous particles that are often found in formulations of therapeutic proteins, particles composed of contaminant matter can be shed into drug products during manufacturing or from product container/closures. Stainless steel microparticles may be shed from filler pumps, ${ }^{17}$ and the US Food and Drug Administration reported that glass particles shed from glass vials have been found in drug products. ${ }^{18}$ Subvisible particles composed of stainless steel and glass can act as potent immunological adjuvants. Van Beers et al. ${ }^{19}$ found that addition of stainless steel microparticles to recombinant interferon beta formulations enhanced immunogenicity of the protein in transgenic mice. Also, addition of glass microparticles to formulations of recombinant murine growth hormone or to formulations of a murine monoclonal antibody elicited significantly higher antibody responses to the respective proteins in mice. ${ }^{20,21}$

Another source of subvisible particles is the lubricant used in prefilled syringes. Prefilled syringes are the primary container of choice for storage and delivery of parenteral drug products because of their ease of use, their compatibility with auto-injectors, and the reduction in improper dosing and decreased contamination associated with their use. ${ }^{22,23}$ Prefilled syringes typically are composed of glass, which requires a lubricant to allow smooth movement of the plunger through the syringe during drug administration. Silicone oil is the most commonly used lubricant in prefilled syringes. Drug products in prefilled syringes are exposed to silicone oil for their entire shelf life because prefilled syringes function as both a delivery device and a storage container. ${ }^{24}$ During shipping and storage, silicone oil may be emulsified from the syringe barrel and form microdroplets of oil in the protein formulation. Also, during administration to patients, movement of the plunger may shed additional silicone oil from the syringe barrel wall into the formulation..$^{23,25}$

Concerns about the stability of proteins in siliconized prefilled syringes arose in the 1980s when clouding and visible precipitates were observed in disposable insulin syringes that contained silicone oil. ${ }^{26-28} \mathrm{~A}$ wide variety of proteins has been shown to adsorb readily to silicone oil microdroplets and proteins may undergo structural perturbations upon adsorption at the silicone oil-water interface. ${ }^{29-32}$ Furthermore, silicone oil may induce protein aggregation and promote particle formation in formulations. ${ }^{29,30,33-37}$ The effect of silicone oil microdroplets on protein structure and assembly state within formulations has been studied for many proteins, but potential immunogenicity consequences of silicone oil microdroplets within protein formulations are less well characterized. An early study by Naim et al. ${ }^{38}$ showed that when rats were injected with bovine serum albumin (BSA) solution that contained silicone oil, there was a small increase in the antibody response relative to that produced by injections of BSA alone. More recently, a study by Shomali et al. ${ }^{39}$ showed that antibody responses were higher in mice administered with formulations of murine monoclonal antibody adsorbed to silicone oil microdroplets relative to oil-free monoclonal antibody formulations. We hypothesize that silicone oil microdroplets will behave similarly to other subvisible particles in formulations and act as an adjuvant to provoke adverse immune responses to administered proteins.
In this study, we investigated the potential of subcutaneously administered silicone oil microdroplets to act as an adjuvant to elicit immune responses in mice against a model foreign protein, ovalbumin (OVA). We measured the antibody response in mice injected with OVA formulations that were spiked with a high concentration silicone oil microdroplet preparation. These responses were compared with responses against OVA formulations without oil and against OVA formulations that contained aluminum hydroxide ("alum"), the common microparticulate vaccine adjuvant. Lastly, we evaluated the antibody response against OVA formulations that contained smaller amounts of silicone oil obtained directly from commercial siliconized syringes. Immune responses were characterized by measuring antibodies against OVA in mouse serum using ELISAs.

Formulations were prepared and characterized the same day as injection. The fraction of protein adsorbed to silicone oil microdroplets and soluble aggregate levels within the formulations were determined using size-exclusion HPLC (SE-HPLC). Particle concentrations were monitored using microflow digital imaging, and tertiary structure changes in adsorbed protein molecules were determined using intrinsic fluorescence quenching.

\section{MATERIALS AND METHODS}

\section{Materials}

Materials used to prepare samples for injection were of United States Pharmacopeia grade or higher. OVA was purchased from Fisher Scientific (Waltham, Massachusetts). Medical grade silicone oil (Dow Corning ${ }^{\circledR}$ 360, 1000 cSt) was obtained from Nexeo Solutions (Denver, Colorado). Aluminum hydroxide adjuvant (Alhydrogel ${ }^{\circledR} 2 \%$ ) was from Brenntag Biosector (Frederikssund, Denmark). EMPROVE ${ }^{\circledR}$ sucrose and $33 \mathrm{~mm}$ diameter syringe filters with $0.22 \mu \mathrm{m}$ pore size polyvinylidene difluoride (PVDF) membranes were obtained from EMD Millipore (Billerica, Massachusetts). Chemicals purchased from Sigma-Aldrich (St. Louis, Missouri) included sodium phosphate monobasic, sodium phosphate dibasic, and BSA. Chemicals purchased from Fisher Scientific included acrylamide, Tris, Tween ${ }^{\mathrm{TM}} 20,10 \times$ phosphate buffered saline (PBS), sulfuric acid, and HyClone ${ }^{\mathrm{TM}}$ water for injection. Acetic acid and hexanes (95\% n-hexane) were from Avantor Performance Materials (Center Valley, Pennsylvania). Peroxidase goat antimouse IgG1, IgG2a, IgG2b, IgG2c, and IgM were purchased from Jackson ImmunoResearch Laboratories, Inc. (West Grove, Pennsylvania). Peroxidase-conjugated goat anti-mouse IgG3 was purchased from Life Technologies (Grand Island, New York). 1-Step ${ }^{\text {TM }}$ Ultra TMB and Immulon ${ }^{\circledR}$ 4HBX 96-well plates were from Thermo Scientific (Waltham, Massachusetts). HSW Norm-Ject ${ }^{\circledR}$ sterile $10 \mathrm{~mL}$ plastic syringes (Henke Sass Wolf, Tuttlingen, Germany) are non-siliconized syringes that were used for syringe filtration of samples for injection so that samples did not come in contact with silicone oil during preparation. HSW Norm-Ject ${ }^{\circledR}$ sterile $1 \mathrm{~mL}$ plastic syringes (Henke Sass Wolf) are non-siliconized syringes and were used for injections through $\mathrm{BD}^{\mathrm{TM}} 25 \mathrm{G} 5 / 8$ inch sterile needles (Becton Dickinson and Company, Franklin Lakes, New Jersey). Goldenrod ${ }^{\mathrm{TM}}$ animal lancets used for mouse submandibular blood draws were purchased from Braintree Scientific, Incorporated (Braintree, Massachusetts). 


\section{Sample Preparation (OVA)}

Ovalbumin was dissolved in $20 \mathrm{mM}$ sodium phosphate buffer ( $\mathrm{pH} 7.4)$ containing $9 \%(\mathrm{w} / \mathrm{v})$ sucrose at a stock concentration of $0.75 \mathrm{mg} / \mathrm{mL}$. The OVA stock solution was drawn into $10 \mathrm{~mL}$ non-siliconized sterile syringes without a needle attached and filtered through a $33 \mathrm{~mm}$ diameter syringe filter with a $0.22 \mu \mathrm{m}$ pore size PVDF membrane. One-milliliter aliquots of OVA stock formulation were stored in $1.5 \mathrm{~mL}$ polypropylene microcentrifuge tubes at $-80^{\circ} \mathrm{C}$ until further use.

Samples for injection into animals were thawed at room temperature. Then, the samples were drawn into $10 \mathrm{~mL}$ nonsiliconized sterile syringes without a needle attached and filtered through a $33 \mathrm{~mm}$ diameter syringe filter with a $0.22 \mu \mathrm{m}$ pore size PVDF membrane. To minimize particle concentrations in silicone oil-free control formulations of OVA, samples were ultracentrifuged at $112,000 \mathrm{~g}$ for $1.5 \mathrm{~h}$ at $4^{\circ} \mathrm{C}$. Centrifuge tubes were filled with $3 \mathrm{~mL}$ of sample and all liquid except for $0.5 \mathrm{~mL}$ at the bottom of the tube was removed and used for experiments. Samples for injection were diluted to a final OVA concentration of $0.25 \mathrm{mg} / \mathrm{mL}$ in $20 \mathrm{mM}$ sodium phosphate buffer ( $\mathrm{pH}$ 7.4) containing $9 \%(\mathrm{w} / \mathrm{v})$ sucrose and administered to mice the same day as prepared. Endotoxin levels were determined using QCL 1000 ${ }^{\mathrm{TM}}$ Limulus Amebocyte Lysate test kit (LONZA, Basel, Switzerland).

\section{Preparation of Silicone Oil Emulsions at High Concentration}

High concentration silicone oil emulsions were prepared using an Emulsiflex ${ }^{\mathrm{TM}}$ C5 high pressure homogenizer (Avestin, Inc., Ottawa, Canada). The procedure of Ludwig et al. ${ }^{29}$ was followed with minor modifications. A $5 \%(\mathrm{v} / \mathrm{v})$ silicone oil in deionized water mixture was sheared at 30,000 rpm for $15 \mathrm{~min}$ using a $20 \mathrm{~mm}$ shaft Virtishear rotor/stator (The VirTis Company, Gardiner, New York). Immediately after shearing, the mixture was passed seven-times through the Emulsiflex ${ }^{\mathrm{TM}}$ C5 at a pressure that oscillated from 1000 to 3000 psi. The silicone oil in water emulsion was then collected in a glass bottle and stored at $4^{\circ} \mathrm{C}$ for up to 2 weeks. The particle size distribution of silicone oil microdroplets in the emulsion was determined using a Beckman Coulter LS230 (Fullerton, California) as described previously. ${ }^{29}$ Zeta potential measurements were taken as described previously ${ }^{31}$ with a Malvern Zetasizer Nano ZS (Worcestershire, United Kingdom).

\section{Preparation of Silicone Oil Emulsions from Commercial Syringes}

Low concentration silicone oil emulsions were created directly from commercially available siliconized syringes (BD Lo-Dose ${ }^{\mathrm{TM}} \mathrm{U}-100$ insulin syringes, Becton Dickinson and Company). Siliconized syringes were filled with $20 \mathrm{mM}$ sodium phosphate buffer ( $\mathrm{pH} 7.4)$ containing 9\% (w/v) sucrose and were sonicated for $2 \mathrm{~h}$ using a Branson 3510 sonicator (Danbury, Connecticut). This treatment emulsified silicone oil from the syringe barrel walls into the buffer. The resulting silicone oilin-buffer emulsions from each syringe were then expelled into a glass vial for storage at $4^{\circ} \mathrm{C}$ for up to $1 \mathrm{~h}$ until use. Silicone oil microdroplets in the emulsions that were prepared in commercial syringes were too dilute for analysis with a Beckman Coulter LS230; instead, droplet size distributions in these samples were determined using dynamic light scattering. Samples were loaded into a $12 \mu \mathrm{L}$ quartz fluorometer cell (Starna Cells Inc., Atascadero, California). Measurements were taken in triplicate using a DynaPro Dynamic Light Scattering instru- ment (Wyatt/ProteinSolutions, Dernbach, Germany) and analyzed using Dynamics V6 ${ }^{\mathrm{TM}}$ version 6.3.40 software (Proterion Corporation, Piscataway, New Jersey). A minimum of 15 acquisitions of $10 \mathrm{~s}$ were collected for each sample at a controlled temperature of $20^{\circ} \mathrm{C}$.

\section{Characterization of Silicone Oil Concentration}

The silicone oil concentration in the emulsion was determined as described previously, ${ }^{29}$ with minor modifications. Silicone oil was extracted into hexane and then analyzed by FTIR spectroscopy. Equal volumes ( $1 \mathrm{~mL})$ of silicone oil emulsion and hexane were combined in $10 \mathrm{~mL}$ glass tubes and prepared in triplicate. Samples were vortexed for $1 \mathrm{~min}$ and then centrifuged at $1200 \mathrm{~g}$ for $1 \mathrm{~h}$ at room temperature. After centrifugation, samples were vortexed for $1 \mathrm{~min}$ and then loaded onto a VariGATR ${ }^{\mathrm{TM}}$ crystal (Harrick Scientific Products Inc., Pleasantville, New York). Hexane was allowed to evaporate before the absorbance was measured at $1220-1300 \mathrm{~cm}^{-1}$ using a Nicolet 6700 FT-IR spectrometer and OMNIC 8.3 software (Thermo Scientific). Silicone oil concentrations in the emulsions were quantified by comparison of the area under the peak at $1260 \mathrm{~cm}^{-1}$ with a standard curve. ${ }^{40}$ The standard curve ranged from 0.099 to $0.78 \mathrm{mg} / \mathrm{mL}$, and standards were measured in quadruplicate. The area under the peak for standards and silicone oil emulsion samples were determined by integration using GRAMS/AI software version 9.1 (Thermo Fisher Scientific).

\section{Adsorption of OVA to Microdroplets}

Emulsions of silicone oil microdroplets or suspensions of alum microparticles were added to OVA formulations. A 1:2 mixture $(\mathrm{v} / \mathrm{v})$ of OVA stock solution to silicone oil emulsion was prepared in order to achieve a final OVA concentration of $0.25 \mathrm{mg} / \mathrm{mL}$ in $20 \mathrm{mM}$ sodium phosphate buffer ( $\mathrm{pH} 7.4$ ) containing $9 \%(\mathrm{w} / \mathrm{v})$ sucrose. For OVA formulations that contained alum, a 1:5 mass ratio of OVA to alum was prepared. Samples containing OVA and particles were transferred into $1.5 \mathrm{~mL} \mathrm{mi-}$ crocentrifuge tubes with a total volume of $1 \mathrm{~mL}$ in each tube and rotated end-over-end at $8 \mathrm{rpm}$ for $1 \mathrm{~h}$ at room temperature to allow the OVA to adsorb to the particles. OVA formulations that contained silicone oil microdroplets or alum microparticles were administered to mice the same day as prepared.

To determine the fraction of protein adsorbed to particles, each sample was centrifuged to separate particles from the aqueous phase. Samples that contained alum were centrifuged at $3000 \mathrm{~g}$ for $10 \mathrm{~min}$ at $4^{\circ} \mathrm{C}$ and supernatant was collected for analysis. Samples that contained silicone oil microdroplets were centrifuged at $20,000 \mathrm{~g}$ for $45 \mathrm{~min}$ at $4^{\circ} \mathrm{C}$ to separate oil and aqueous phases. A volume of $0.2-0.3 \mathrm{~mL}$ of the aqueous subnatant phase was collected from the bottom of each tube using a needle and syringe. Subsequently, the samples were analyzed in triplicate using SE-HPLC to quantify the amount of monomer remaining in solution. Adsorbed OVA amounts were estimated by mass balance.

\section{Size-Exclusion HPLC}

SE-HPLC was used to identify the amount of monomer and high-molecular-weight species (HMWS) in samples. A TSKgel $\mathrm{G} 000 \mathrm{SW}_{\mathrm{XL}}$ column (TOSOH Biosciences, Montgomeryville Pennsylvania) was used with a Beckman System Gold ${ }^{\circledR}$ HPLC (Beckman Coulter). The mobile phase consisted of PBS composed of $11.9 \mathrm{mM}$ phosphates, $137 \mathrm{mM}$ sodium chloride, 
$2.7 \mathrm{mM}$ potassium chloride ( $\mathrm{pH}$ 7.4). The flow rate used was $0.8 \mathrm{~mL} / \mathrm{min}$, and $100 \mu \mathrm{L}$ of each sample were injected into the column. The absorbance of the eluent was monitored at $280 \mathrm{~nm}$ using a System Gold ${ }^{\circledR} 168$ detector and 32 Karat $^{\mathrm{TM}}$ analysis software. Chromatograms were analyzed in GRAMS/AI software version 9.1 (Thermo Fisher Scientific Inc.). Areas under peaks were determined by integration. The fraction of protein adsorbed to silicone oil microdroplets or alum microparticles was determined by the following equation:

Fraction of protein adsorbed $=\left(1-\frac{\text { area under peak }_{\text {sample }}}{\text { area under peak }_{\text {control }}}\right)$

Control samples consisted of protein samples without silicone oil microdroplets or alum microparticles and were treated identically to protein samples that contained particles.

\section{Particle Analysis (FlowCAM)}

Particle concentrations in samples administered to mice were measured using FlowCAM ${ }^{\circledR}$ (Fluid Imaging Technologies, Scarborough, Maine), a microflow digital imaging technique that detects particles between 2 and $100 \mu \mathrm{m}$. The protocol followed is previously described in Gerhardt et al. ${ }^{34}$ Samples were measured in triplicate.

\section{Intrinsic Fluorescence Quenching of Adsorbed OVA}

Tertiary structural changes in OVA following adsorption to particles or microdroplets were monitored using intrinsic fluorescence quenching of OVA tryptophan residues. An SLM Aminco Fluorimeter (SLM Instruments, Urbana, Illinois) was used to monitor the fluorescence intensity. The protocol followed was previously described in Gerhardt et al. ${ }^{30}$ Samples and controls included native OVA, OVA adsorbed to emulsified silicone oil microdroplets, OVA adsorbed to alum microparticles, and OVA unfolded in $8 \mathrm{M}$ urea $25 \mathrm{mM}$ dithiothreitol (DTT) at a concentration of $0.2 \mathrm{mg} / \mathrm{mL}$. Samples were analyzed in triplicate. To determine the extent of fluorescence quenching, data were graphed in the form of a Stern-Volmer plot according to the equation:

$$
\frac{F_{0}}{F}=1+K_{\mathrm{SV}}[Q]
$$

where $F_{0}$ is fluorescence intensity at the emission maximum in the absence of quencher, $F$ is the fluorescence intensity at the emission maximum in the presence of quencher (acrylamide), $[Q]$ is the quencher concentration, and $K_{\mathrm{SV}}$ is the Stern-Volmer constant. Stern-Volmer constants $\left(K_{\mathrm{SV}}\right)$ were obtained from the initial slope of the plot and indicate the relative accessibility of solvent to tryptophan residues in the protein.

\section{Immunogenicity Testing in Animals}

Animal experiments described in protocol 1210.03 were approved by the University of Colorado Institutional Animal Care and Use Committee. Adult female CB6F1 (BALB/c $\times$ C57 BL/6) mice greater than 6 weeks of age were purchased from Charles River Laboratories, Inc. (Wilmington, Massachusetts). Four or five mice were housed in each sterile, air-filtered cage with food and water available $a d$ libitum. Mice were allowed to acclimate for a minimum of one week before the start of the study. Subcutaneous injections were administered to mice in the scruff of the neck on days 1 and 15 . Samples were administered using non-siliconized syringes, and each injection of $200 \mu \mathrm{L}$ contained $50 \mu \mathrm{g}$ of OVA. Groups of five to eight mice were treated with OVA, OVA that contained emulsified silicone oil microdroplets at $3.2 \pm 0.5 \mathrm{mg} / \mathrm{mL}$, OVA that contained syringe-extracted silicone oil microdroplets at $0.11 \pm 0.03 \mathrm{mg} / \mathrm{mL}$, and OVA that contained alum microparticles at $1.25 \mathrm{mg} / \mathrm{mL}$. Also, control groups of mice were injected with buffer or with protein-free buffer that contained emulsified silicone oil microdroplets. Submandibular blood draws were performed before the start of the study to serve as a baseline for each mouse, as well as on day 11 and 29 to capture primary and secondary immune responses. Blood samples were collected in sterile microcentrifuge tubes and placed on ice. Subsequently, samples were centrifuged at $15,000 \mathrm{rpm}$ for $10 \mathrm{~min}$ at $4^{\circ} \mathrm{C}$. Serum was then obtained and stored in aliquots at $-80^{\circ} \mathrm{C}$ until further analysis.

\section{Anti-OVA ELISA}

Antibodies specific to OVA were measured using indirect ELISA. Immulon ${ }^{\circledR} 4 \mathrm{HBX}$ plates were coated with $10 \mu \mathrm{g} / \mathrm{mL}$ OVA in $20 \mathrm{mM}$ Tris at pH $8.5(100 \mu \mathrm{L} /$ well $)$ and incubated overnight at room temperature with gentle agitation. Plate wells were drained and then treated with $300 \mu \mathrm{L}$ of blocking solution [PBS (pH 7.4), 2\% BSA, 0.05\% Tween $20^{\circledR}$ ] for $1.5 \mathrm{~h}$. Plates were washed three times with wash buffer (PBS, $0.05 \%$ Tween $20^{\circledR}$ ) using an EL $\times 50$ plate washer (BioTek, Winooski, Vermont). Dilution buffer [PBS (pH 7.4), $2 \%$ BSA, $0.05 \%$ Tween $\left.20^{\circledR}\right]$ was then added to plates $(50 \mu \mathrm{L} /$ well). Serum samples were pretreated in $300 \mathrm{mM}$ acetic acid for $1 \mathrm{~h} .{ }^{41}$ After $\mathrm{pH}$ adjustment to 7.4 with $1 \mathrm{M}$ Tris buffer ( $\mathrm{pH} 9.5$ ), $50 \mu \mathrm{L}$ of diluted serum samples were immediately transferred to the first row of the plate. Samples were serially diluted down the plate in dilution buffer and incubated for $1 \mathrm{~h}$. Plates were washed five times with wash buffer. Next, goat anti-mouse antibodies conjugated to horseradish peroxidase of subclass IgG1, IgG2a, IgG2b, IgG2c, IgG3, or IgM were diluted in blocking solution and added to the wells ( $50 \mu \mathrm{L} /$ well). The CB6F1 (the F1 generation from a $\mathrm{BALB} / \mathrm{c} \times \mathrm{C} 57 \mathrm{BL} / 6$ cross) mouse strain can produce both IgG2a and IgG2c immunoglobulin isotypes as the IgG2a immunoglobulin isotype is encoded by the parental BALB/c mouse strain and the IgG2c isotype is derived from the $\mathrm{C} 57 \mathrm{BL} / 6$ strain. After secondary incubation for $1 \mathrm{~h}$, the plates were washed five times. Substrate solution 1-Step ${ }^{\mathrm{TM}}$ Ultra TMB was added ( $50 \mu \mathrm{L} /$ well). After $25 \mathrm{~min}$, the reaction was stopped by addition of $30 \mu \mathrm{L}$ of $0.5 \mathrm{M}$ sulfuric acid. Absorbance was measured at $450 \mathrm{~nm}$ using a Vmax ${ }^{\circledR}$ microplate reader (Molecular Devices Corporation, Sunnyvale, California). Absorbance values were used to determine endpoint titers for each mouse. We defined endpoint titer as the reciprocal of the highest dilution that gave a signal above the cutoff. Cutoff values were calculated for each mouse using pretreatment blood drawn at day 0 and a statistically defined endpoint titer determination method published previously. ${ }^{42}$ For graphical presentation, murine serum samples with absorbance values less than the cutoff value were assigned an arbitrary titer value of one.

\section{Statistical Analysis}

SigmaPlot ${ }^{\circledR} 12.2$ software (Systat Software Inc., San Jose, California) was used to perform statistical analyses. Nonparametric Mann-Whitney tests were performed to determine statistical differences in titer values between experimental groups. 
The sample size for each experimental group was equal to eight. Differences between experimental groups with $\mathrm{p}$ values less than 0.05 were considered significant.

\section{RESULTS}

\section{Characterization of Silicone Oil Emulsions and Alum Microparticles}

Silicone oil emulsions were created by two different methods. In the first method, emulsions containing relatively high concentrations of silicone oil were created using a high pressure homogenizer and are referred to as "emulsified silicone oil" microdroplets. In the second method, lower concentration silicone oil emulsions were created that contained levels of silicone oil equivalent to those found in a commercial syringe. Silicone oil microdroplets were emulsified directly from the syringe barrel of commercial siliconized syringes using sonication and are referred to as "syringe-extracted silicone oil" microdroplets. The concentration of silicone oil in each of the two types of emulsions was determined using FTIR spectroscopy. In emulsions created by sonicating commercially available siliconized syringes, the silicone oil concentration was $0.16 \pm 0.05 \mathrm{mg} / \mathrm{mL}$. In contrast, emulsions prepared using a high pressure homogenizer contained $5.4 \pm 0.8 \mathrm{mg} / \mathrm{mL}$ silicone oil.

Laser diffraction analysis was used to obtain the particle size distributions of silicone oil microdroplets in the emulsion and of alum microparticles in suspension (Fig. 1). The mean diameters of emulsified silicone oil microdroplets and alum microparticles were $0.111 \pm 0.002$ and $0.100 \pm 0.001 \mu \mathrm{m}$, respectively. As determined by DLS, the mean diameters of syringe-extracted silicone oil microdroplets and emulsified silicone oil microdroplets were $0.140 \pm 0.020$ and $0.130 \pm 0.040 \mu \mathrm{m}$, respectively. The zeta potentials of emulsified silicone oil microdroplets in water ranged from -73 to $-85 \mathrm{mV}$. The highly negative zeta potential confirmed that the silicone oil emulsions were colloidally stable, as shown previously. ${ }^{29,31}$

\section{Characterization of OVA Formulations containing Microparticles}

Using SE-HPLC, no soluble HMWS were detected in OVA formulations with or without silicone oil microdroplets or alum microparticles (data not shown). In OVA formulations that contained emulsified silicone oil microdroplets at $3.2 \pm 0.5 \mathrm{mg} / \mathrm{mL}$, the fraction of protein adsorbed to silicone oil microdroplets was $0.5 \pm 0.2(0.125 \pm 0.050 \mathrm{mg}$ protein adsorbed $/ \mathrm{mL})$. The fraction of protein adsorbed to silicone oil microdroplets was $0.10 \pm 0.07$ $(0.025 \pm 0.018 \mathrm{mg}$ protein adsorbed $/ \mathrm{mL})$ in OVA formulations that contained syringe-extracted silicone oil microdroplets at a lower concentration of $0.11 \pm 0.03 \mathrm{mg} / \mathrm{mL}$. In samples that contained syringe-extracted silicone oil microdroplets, the majority of protein administered to mice was unadsorbed and remained in solution because the relatively low concentration of silicone oil microdroplets in these emulsions provided insufficient surface area for adsorption of a significant amount of the protein. For samples that contained alum microparticles at $1.25 \mathrm{mg} / \mathrm{mL}$, the fraction of protein adsorbed was $0.16 \pm 0.05(0.04 \pm 0.01 \mathrm{mg}$ protein adsorbed $/ \mathrm{mL}$ ). Figure 2 displays particle concentrations in samples for injection measured using microflow digital imaging with FlowCAM ${ }^{\circledR}$. After filtration and ultracentrifugation of formulations of OVA to minimize particles, concentrations were reduced to $\sim 100$ particles $/ \mathrm{mL}$. After addition of silicone oil microdroplets or alum microparticles to OVA formulations,
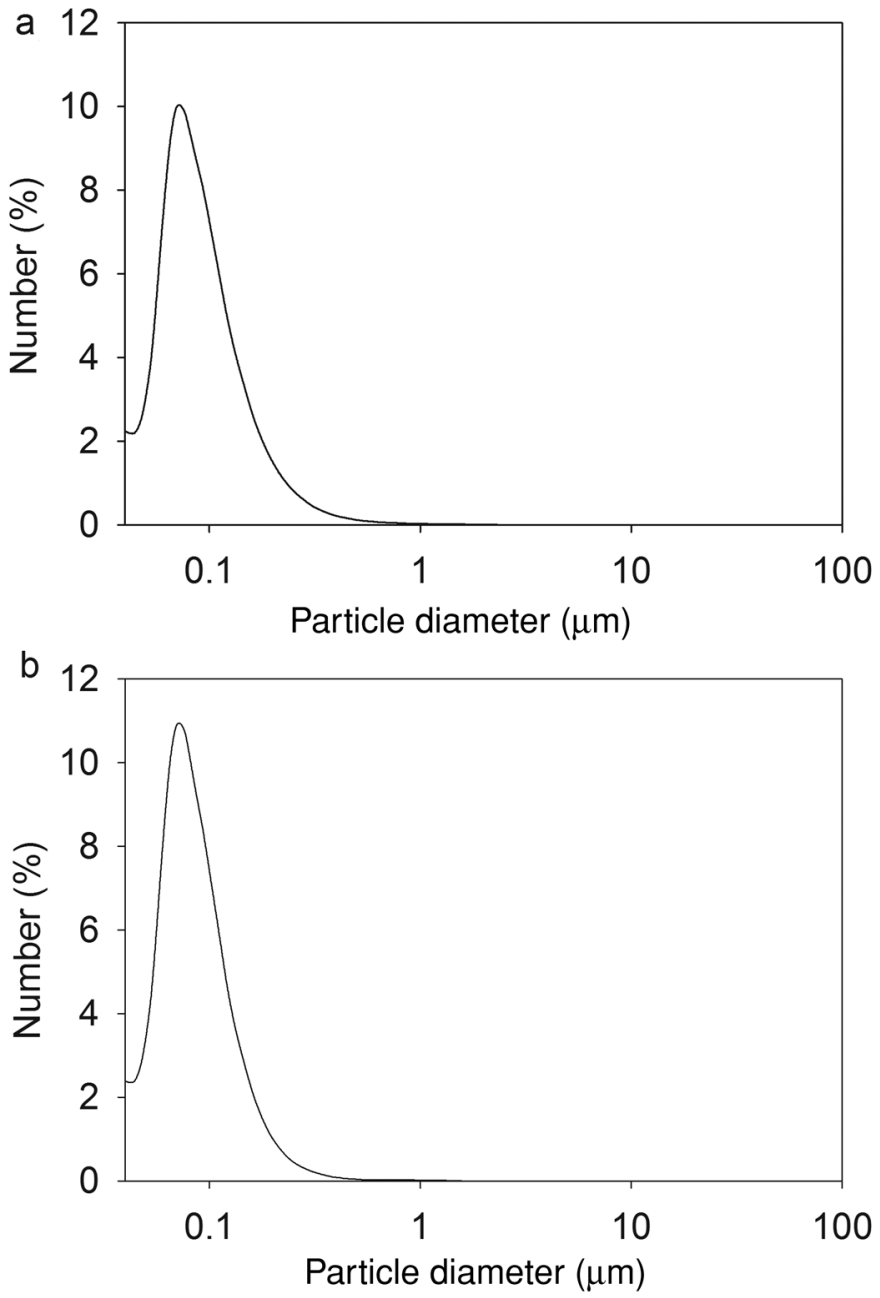

Figure 1. The number-weighted particle size distribution of a silicone oil in water emulsion (a) and a suspension of alum microparticles (b) was determined using laser diffraction. The mean diameter of silicone oil microdroplets in the emulsions and alum microparticles in suspension was $0.111 \pm 0.002 \mu \mathrm{m}$ and $0.100 \pm 0.001 \mu \mathrm{m}$, respectively.

concentrations of particles in the micron range increased by three to five orders of magnitude to $10^{6}$ to $10^{8}$ particles $/ \mathrm{mL}$.

Endotoxin levels ${ }^{43}$ for formulations of buffer, buffer that contained emulsified silicone oil microdroplets, and OVA were 0.1, 0.7, and 0.3 EU/mL, respectively. Endotoxin levels for formulations of OVA that contained emulsified silicone oil microdroplets, OVA formulations that contained syringe-extracted silicone oil microdroplets, and OVA formulations that contained alum were $1.0,0.6$, and $1.7 \mathrm{EU} / \mathrm{mL}$, respectively.

\section{Tertiary Structure Changes of Adsorbed OVA Using Intrinsic Fluorescence Quenching}

The Stern-Volmer plots for native OVA, OVA adsorbed to emulsified silicone oil microdroplets, OVA adsorbed to alum, and OVA unfolded in $8 \mathrm{M}$ urea $25 \mathrm{mM}$ DTT are shown in Figure 3. Stern-Volmer constants $\left(K_{\mathrm{sv}}\right)$ were obtained from the initial slope of the plot and indicate the relative accessibility of solvent to tryptophan ( $\operatorname{Trp})$ residues in the protein. As expected, the Stern-Volmer constant of unfolded OVA $\left(K_{\mathrm{sv}}=8.7 \pm 0.1\right)$ was substantially higher than that of native OVA $\left(K_{\mathrm{sv}}=3.2 \pm 0.1\right)$, 


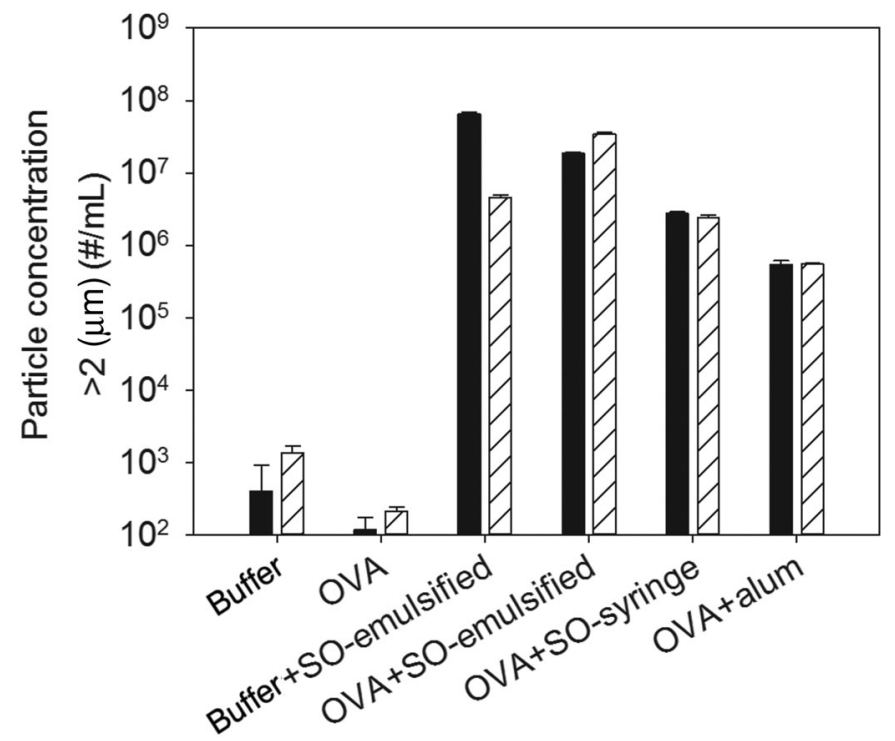

Figure 2. Particle concentrations in formulations of buffer, OVA, buffer that contained emulsified silicone oil microdroplets, OVA that contained emulsified silicone oil microdroplets, OVA that contained syringe-extracted silicone oil microdroplets, and OVA formulations that contained alum. Particle concentrations were measured by FlowCAM ${ }^{\circledR}$ which detects particles between 2 and $100 \mu \mathrm{m}$ in the formulations that were injected into mice on day 1 (solid) and day 15 (striped). Particle concentrations were three to five orders of magnitude higher for formulations that contained silicone oil microdroplets and alum microparticles compared with formulations of buffer or OVA. Error bars represent the standard deviation from the average of three replicates.

indicating a greater solvent accessibility to Trp residues when the protein is unfolded. When OVA was adsorbed to silicone oil, the Stern-Volmer constant was larger $\left(K_{\mathrm{sv}}=5.9 \pm 0.8\right)$ than that for native OVA. This suggests an increase in solvent acces-

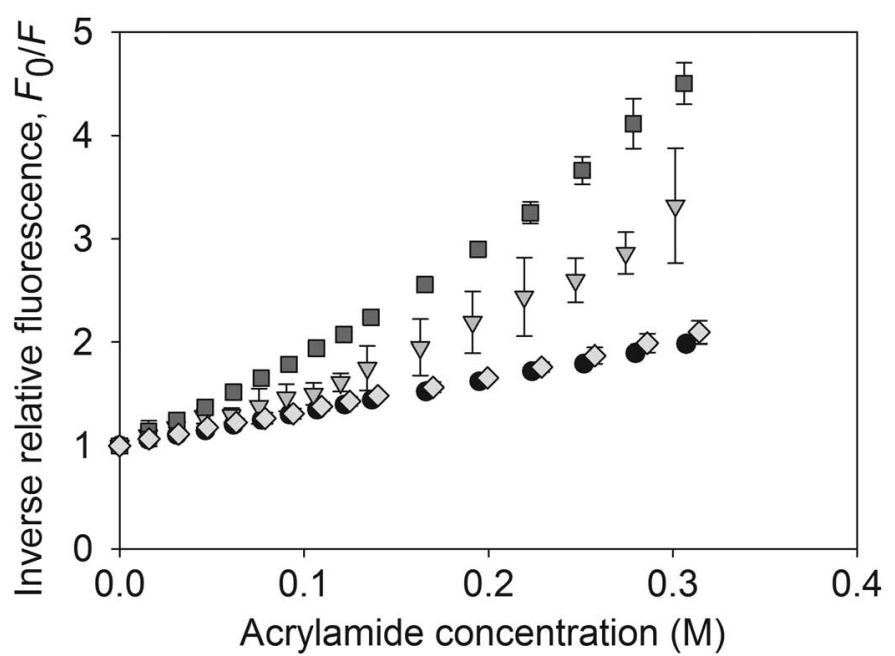

Figure 3. Stern-Volmer plots of inverse relative fluorescence versus acrylamide concentration for native OVA (circles), OVA adsorbed to silicone oil microdroplets (triangles), OVA adsorbed to alum (diamonds), and OVA unfolded in $8 \mathrm{M}$ urea $25 \mathrm{mM}$ DTT (squares). Stern-Volmer constants were obtained from the slope of the initial linear portion of the plot. Error bars represent the SD from the average of three replicates.
Table 1. The Number of Mice in Each Group Showing Anti-OVA Antibodies at Day 29

\begin{tabular}{lcccccc}
\hline Mouse Group & IgG1 & IgG2a & IgG2b & IgG2c & IgG3 & IgM \\
\hline Buffer & $1 / 5$ & $0 / 5$ & $0 / 5$ & $0 / 5$ & $0 / 5$ & $0 / 5$ \\
Buffer + emulsified & $0 / 5$ & $0 / 5$ & $1 / 5$ & $0 / 5$ & $0 / 5$ & $0 / 5$ \\
$\quad$ silicone oil & & & & & & \\
OVA & $5 / 8$ & $0 / 8$ & $3 / 8$ & $0 / 8$ & $4 / 8$ & $3 / 8$ \\
OVA + emulsified & $8 / 8$ & $4 / 8$ & $5 / 8$ & $2 / 8$ & $4 / 8$ & $2 / 8$ \\
$\quad$ silicone oil & & & & & & \\
\hline
\end{tabular}

sibility to OVA Trp residues and a perturbation in the tertiary structure of the protein adsorbed to silicone oil. The SternVolmer constant of OVA adsorbed to alum $\left(K_{\mathrm{sv}}=3.5 \pm 0.1\right)$ was similar to that of native OVA indicating a minimal change in tertiary structure when adsorbed.

\section{Immunogenicity of OVA Formulations Containing Silicone Oil at High Concentration}

Table 1 shows the number of mice in each group after the final injection at day 29 showing anti-OVA antibodies for mice treated with buffer, buffer that contained emulsified silicone oil microdroplets, OVA, and OVA that contained emulsified silicone oil microdroplets. As expected, groups of mice injected with buffer or buffer that contained emulsified silicone oil microdroplets did not exhibit an antibody response. At least half of the mice treated with OVA alone showed IgG1 and IgG3 antibodies against OVA and over one third of the mice produced anti-OVA IgG2b and IgM. Anti-OVA IgG2a or IgG2c antibodies were not detected in mice treated with OVA alone. When emulsified silicone oil microdroplets were present in in OVA formulations, all six antibody subclasses were detected and $100 \%$ of the mice produced an IgG1 antibody response. Anti-OVA antibody titers for each mouse after the final injection at day 29 are shown in Figure 4. When administered with emulsified silicone oil microdroplets, OVA formulations elicited strong anti-OVA IgG1 and IgG2a antibody responses (Figs. $4 \mathrm{a}$ and $4 \mathrm{~b}$ ) that were significantly increased relative to mice injected with OVA alone at day $29(p=0.002, p=0.032$; Table 3$)$. No significant differences in anti-OVA titers for IgG2b, IgG2c, IgG3, and IgM at day 29 were detected after the addition of emulsified silicone oil microdroplets to OVA formulations (Figs. $4 \mathrm{c}$ and 4f; Table 3). No significant differences in anti-OVA titers were detected at day 11 for any isotype tested. Total IgG concentrations measured by ELISAs did not change over time within error and were independent of treatment indicating that antigen non-specific $B$ cell stimulation (e.g., by endotoxin) and subsequent antibody production did not contribute to these responses. Thus, our results showed that addition of silicone oil microdroplets to OVA formulations provoked a robust antibody response against OVA in mice.

\section{Immunogenicity of OVA Formulations Containing Alum or Silicone Oil from Commercial Syringes}

Table 2 shows the number of mice in each group after the final injection at day 29 showing anti-OVA antibodies for mice treated with formulations of OVA, OVA that contained emulsified silicone oil microdroplets, OVA that contained syringeextracted silicone oil microdroplets, and OVA that contained alum microparticles. For mice treated with OVA formulations that contained emulsified silicone oil microdroplets or alum 

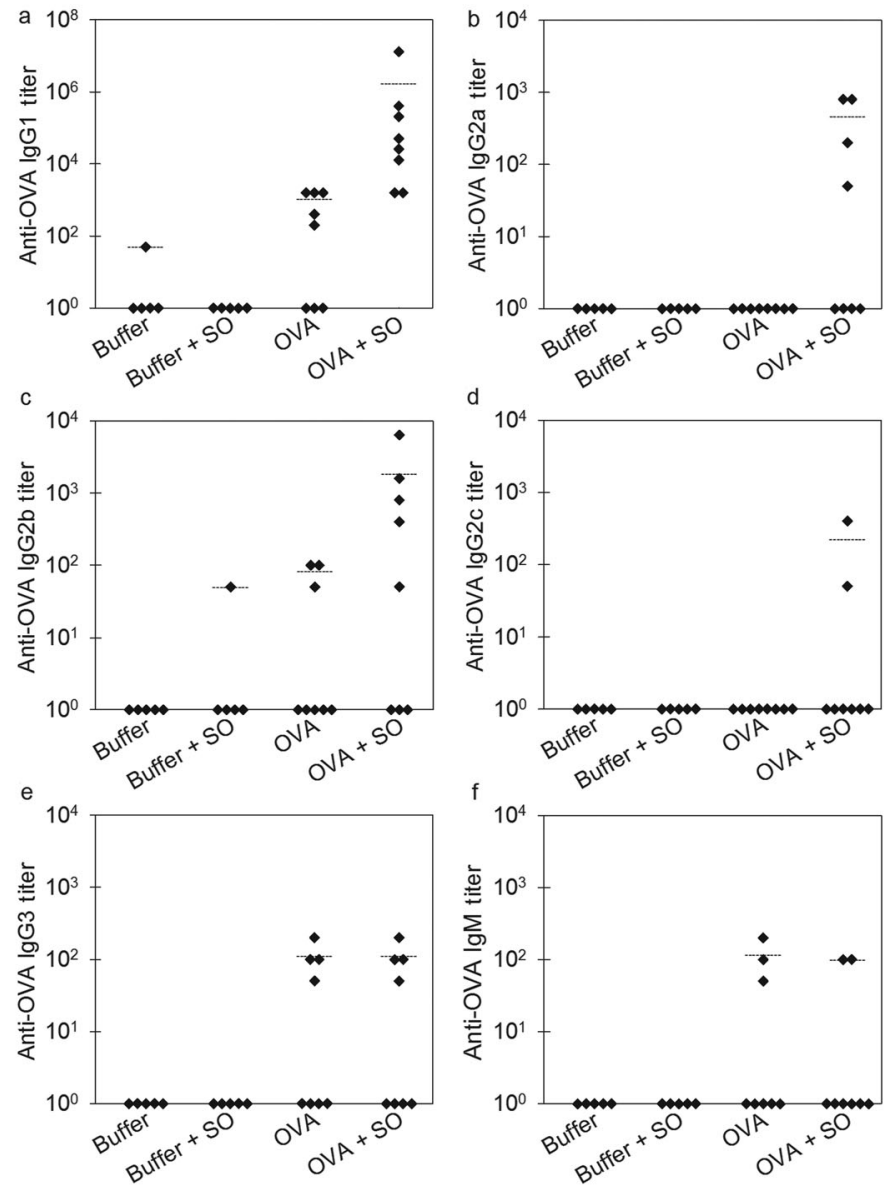

Figure 4. Anti-OVA antibody titers for mice treated with formulations of buffer, buffer that contained emulsified silicone oil microdroplets, OVA, and OVA that contained emulsified silicone oil microdroplets at day 29 for IgG1 isotype (a), IgG2a isotype (b), IgG2b isotype (c), IgG2c isotype (d), IgG3 isotype (e), and IgM isotype (f). Each data point represents the titer value of an individual mouse. Bars represent the average titer of mice that responded within that group.

microparticles, all six antibody subclasses were detected and $100 \%$ of mice from both groups produced an IgG1 antibody response. Anti-OVA antibody titers for mice treated with the various OVA formulations after the final injection are shown in Figure 5. Mice treated with OVA formulations that contained alum microparticles also produced higher IgG1 and IgG2a titers relative to mice injected with OVA alone $(p<0.001$, $p=0.076$; Table 3). The strong IgG1 and IgG2a responses elicited by OVA formulations that contained alum micropar-

Table 2. The Number of Mice in Each Group Treated with Various OVA Formulations Showing Anti-OVA Antibodies at Day 29

\begin{tabular}{|c|c|c|c|c|c|c|}
\hline Mouse Group & IgG1 & IgG2a & $\operatorname{IgG} 2 b$ & $\operatorname{IgG} 2 \mathrm{c}$ & IgG3 & IgM \\
\hline OVA & $5 / 8$ & $0 / 8$ & $3 / 8$ & $0 / 8$ & $4 / 8$ & $3 / 8$ \\
\hline $\begin{array}{l}\text { OVA + emulsified } \\
\text { silicone oil }\end{array}$ & $8 / 8$ & $4 / 8$ & $5 / 8$ & $2 / 8$ & $4 / 8$ & \\
\hline $\begin{array}{l}\text { OVA + } \\
\text { syringe-extracted } \\
\text { silicone oil }\end{array}$ & $7 / 8$ & $1 / 8$ & $3 / 8$ & $0 / 8$ & $6 / 8$ & \\
\hline OVA + alum & $8 / 8$ & $3 / 8$ & $8 / 8$ & $1 / 8$ & $6 / 8$ & $4 / 8$ \\
\hline
\end{tabular}

ticles were equivalent to those observed when emulsified silicone oil microdroplets were added to the OVA formulations (Figs. 5a and 5b; Table 3). Anti-OVA IgG2b titers were also similar between mice treated with OVA formulations that contained alum microparticles or silicone oil microdroplets (Fig. 5c; Table 3). Addition of silicone oil microdroplets or alum microparticles did not significantly enhance the IgG2c, IgG3, or IgM response relative to mice injected with OVA alone at day 29 (Figs. 5d and 5f; Table 3). No significant increase in anti-OVA titers were detected at day 11 for any isotype tested. Our findings showed that silicone oil microdroplets can act as a potent adjuvant when compared with alum.

We also compared the antibody response to OVA formulations that contained relatively low levels of silicone oil that were directly emulsified from the barrel of commercial siliconized syringes against responses to OVA formulations prepared with higher-concentration silicone oil emulsions made using a high-pressure emulsifier. Similar numbers of mice responded when injected with OVA formulations that contained syringeextracted silicone oil microdroplets or with OVA formulations that contained emulsified silicone oil microdroplets (Table 2), but anti-OVA titers for mice injected with syringe-extracted silicone oil microdroplets were not enhanced significantly relative to mice injected with OVA alone (Fig. 5 and Table 3). Thus, the anti-OVA antibody response was dependent on the concentration of silicone oil microdroplets in OVA formulations.

\section{DISCUSSION}

To determine if silicone oil was capable of acting as an adjuvant, we first measured the antibody response in mice injected with oil-free OVA formulations and OVA formulations that contained emulsified silicone oil microdroplets at high concentration. As expected, OVA provoked an antibody response in mice because OVA is not endogenously expressed in mice and thus is recognized as foreign. ${ }^{44}$ However, when administered with emulsified silicone oil microdroplets, OVA formulations elicited more robust anti-OVA IgG1 and IgG2a responses in mice relative to those produced by injection of oil-free OVA formulations. Thus, our findings show that silicone oil microdroplets can act as an adjuvant to provoke antibody responses against OVA. It is important to note that the concentration of silicone oil present in our high-concentration silicone oil formulations is about five to ten times the amount found in commercial siliconized syringes. ${ }^{45}$

We compared antibody responses against formulations that contained emulsified silicone oil microdroplets to responses against formulations that contained alum, the common vaccine adjuvant. OVA formulations that contained either silicone oil microdroplets or alum microparticles produced equivalent anti-OVA antibody responses, suggesting that silicone oil microdroplets are as potent as that of the vaccine adjuvant, alum. In the development of vaccine formulations, where production of antibodies against the antigen is desired, particlebased adjuvants that adsorb antigen are commonly added to formulations to increase the immunogenicity of the antigen. ${ }^{46}$ Multiple mechanisms of action for these adjuvants have been proposed. It has been postulated that particle-based adjuvants can increase antigen persistence at the injection site which can enhance uptake of antigen by antigen presenting cells. ${ }^{46}$ Alum can also stimulate an immune response by activation of 
Table 3. Calculated $p$ Values for Anti-OVA Antibody Titers at Day 29 Between Experimental Groups

\begin{tabular}{|c|c|c|c|c|}
\hline Isotype & Formulation & OVA + Emulsified SO & OVA + Syringe-Extracted SO & $\mathrm{OVA}+$ Alum \\
\hline \multirow[t]{2}{*}{ IgG1 } & OVA & \multirow[t]{2}{*}{0.002} & 0.219 & $<0.001$ \\
\hline & OVA + emulsified SO & & 0.011 & NS \\
\hline \multirow[t]{2}{*}{$\operatorname{IgG} 2 \mathrm{a}$} & OVA & \multirow[t]{2}{*}{0.032} & 0.382 & 0.076 \\
\hline & OVA + emulsified SO & & 0.11 & NS \\
\hline \multirow[t]{2}{*}{ IgG2b } & OVA & \multirow[t]{2}{*}{0.16} & NS & $<0.001$ \\
\hline & $\mathrm{OVA}+$ emulsified SO & & 0.16 & 0.485 \\
\hline \multirow[t]{2}{*}{ IgG2c } & OVA & \multirow[t]{2}{*}{0.171} & NS & 0.382 \\
\hline & OVA + emulsified SO & & 0.171 & NS \\
\hline \multirow[t]{2}{*}{ IgG3 } & OVA & \multirow[t]{2}{*}{ NS } & NS & NS \\
\hline & OVA + emulsified SO & & NS & NS \\
\hline \multirow[t]{2}{*}{$\operatorname{IgM}$} & OVA & \multirow[t]{2}{*}{ NS } & 0.076 & NS \\
\hline & OVA + emulsified SO & & 0.17 & 0.247 \\
\hline
\end{tabular}

NS, not significant.
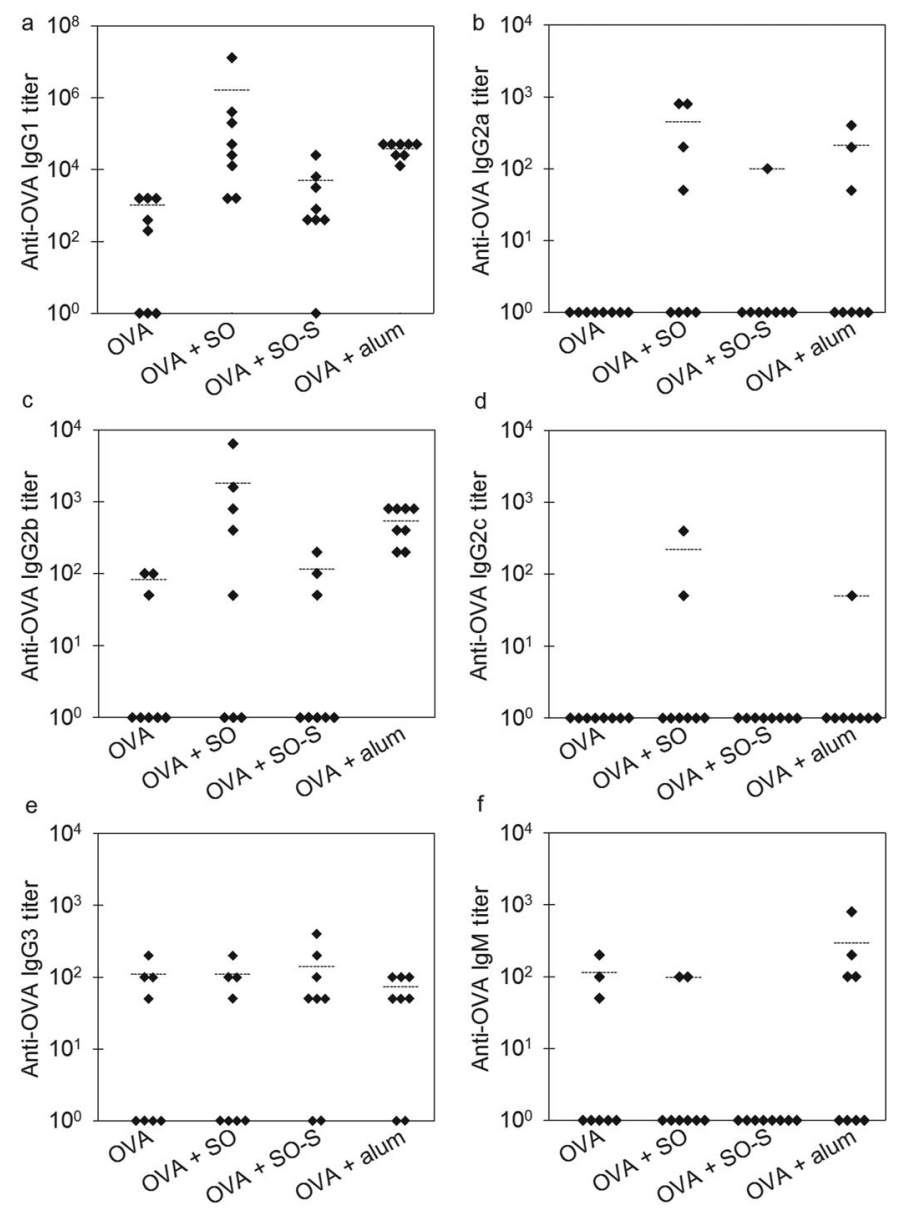

Figure 5. Anti-OVA antibody titers for mice treated with formulations of OVA, OVA that contained emulsified silicone oil microdroplets (OVA + SO), OVA that contained syringe-extracted silicone oil microdroplets (OVA + SO-S), and OVA that contained alum (OVA + alum) at day 29 for IgG1 isotype (a), IgG2a isotype (b), IgG2b isotype (c), IgG2c isotype (d), IgG3 isotype (e), and IgM isotype (f). Each data point represents the titer value of an individual mouse. Bars represent the average titer of mice that responded within the group.

the NLRP3 inflammasome pathway and production of proinflammatory cytokines. ${ }^{47}$ Alum is known to induce a T-celldependent immune response that results in production of IgG1 and IgG2a antibodies. ${ }^{48-50}$ In our study, mice treated with OVA formulations that contained alum produced an antibody response consistent with a T-cell-dependent immune response. The enhanced IgG1 and IgG2a responses exhibited in mice treated with OVA formulations that contained silicone oil microdroplets also is consistent with a T-cell-dependent immune response.

The adjuvant potential of emulsions composed of oil and water has been known for decades. ${ }^{46}$ Complete Freund's adjuvant (CFA) and incomplete Freund's adjuvant (IFA) are emulsions that contain a high oil content. They are not approved for use in humans because of safety issues, but have been commonly used in animal models. MF59, which is a $4 \%(\mathrm{v} / \mathrm{v})$ oil in water emulsion, is an emulsion-based vaccine adjuvant that is approved for use in Europe. MF59 is similar in composition and mean particle size $(160 \mathrm{~nm})$ to the formulations used in our studies that contained emulsified silicone oil microdroplets. ${ }^{51}$ Studies by Singh et al. ${ }^{52}$ showed that MF59 was more potent at generating antibodies than alum for a variety of antigens including bacterial toxoids, polysaccharide conjugates, and recombinant antigens in mice. Our studies showed that silicone oil produced an IgG1 response indistinguishable from that produced by alum.

In our studies, one important difference between OVA formulations that contained silicone oil microdroplets compared with OVA formulations that contained alum microparticles was that adsorption to the silicone oil microdroplets induced structural perturbations in OVA, whereas OVA adsorbed to alum retained near-native structure, in agreement with previous literature. ${ }^{20,21,30,37}$ Conformational changes that occur to protein adsorbed to particles may influence immunogenicity, ${ }^{7}$ perhaps by creating or exposing new conformational epitopes that have higher potential to elicit an immune response. Similar antibody responses against the native form of OVA were detected in mice administered with OVA formulations that contained emulsified silicone oil microdroplets or alum microparticles despite the differences in protein conformational changes in the samples. Also, although the mean particle sizes within our formulations containing silicone oil microdroplets were similar to those in formulations containing alum microparticles, the concentrations of particles with sizes greater than $2 \mu \mathrm{m}$ were two orders of magnitude higher in the silicone oil-containing formulations than in the alum-containing formulations. The concentration of particles may influence the level of response. In earlier studies, samples with the highest particle concentration resulted in the strongest immune response. ${ }^{14,15}$ 
Because the concentration of silicone oil in our emulsified silicone oil samples was higher than the amount found in commercial siliconized syringes, we evaluated the antibody response of OVA formulations that contained lower levels of silicone oil equivalent to the amount in commercial syringes. Our studies showed that the level of antibody response is dependent on the concentration of silicone oil microdroplets in the formulation. Similar numbers of mice responded when injected with OVA that contained the lower-concentration syringe-extracted silicone oil or the higher-concentration emulsified silicone oil microdroplets, but antibody responses to formulations of OVA that contained syringe-extracted silicone oil were not enhanced significantly compared with responses against OVA alone. The strong antibody response elicited by OVA formulations with emulsified silicone oil microdroplets contained higher particle concentrations and a considerably larger amount of conformationally perturbed OVA was adsorbed to silicone oil microdroplets compared with formulations that contained syringe-extracted silicone oil microdroplets. Our study does not allow us to discern if the enhanced immune response was due to increased particle concentrations, the fraction of adsorbed and structurally perturbed protein in the formulation, or both. Also, the relatively high background immune response to OVA alone made any enhancement of the immune response due to added silicone oil microdroplets harder to distinguish with the sample size that was used.

It is possible that levels of silicone oil present in commercial syringes could provoke an immune response. Because our samples were injected the same day as prepared for our study, the exposure time of OVA to silicone oil microdroplets was minimal $(<8 \mathrm{~h})$. Typical shelf lives for prefilled syringe products are at least one year. ${ }^{24}$ Therefore, therapeutic proteins in prefilled syringes are exposed to silicone oil for longer times which could increase the immunogenicity of the drug product.

The robust IgG1 and IgG2a responses and weak IgG2b, Ig2c, and IgG3 responses elicited by silicone oil microdroplets are characteristic of a T-cell-dependent immune response. The immune system can also be activated by a T-cell-independent B cell activation mechanism which is associated with higher levels of IgG3 in the mouse. ${ }^{53}$ In our studies, addition of silicone oil microdroplets to OVA formulations did not significantly increase IgG3 titers relative to OVA alone, suggesting that silicone oil does not act in a T-cell independent fashion to enhance the immunogenicity of proteins. Likewise, formulations that contained silicone oil microdroplets did not generate significant IgG2b or IgG2c responses, which are effective anti-pathogen immunoglobulin isotypes. ${ }^{54,55} \mathrm{An}$ IgM response is indicative of an early response secreted by newly exposed B cells that have not undergone isotype switching. ${ }^{56}$ At the end of the study, no significant IgM responses were detected, likely reflecting the relatively late time point, by which isotype switching to IgG had already occurred.

\section{CONCLUSIONS}

Silicone oil that is used as a lubricant in prefilled syringes can be expelled into drug products in the form of suspended microdroplets. In this study, we found that the presence of silicone oil microdroplets in OVA formulations caused structural perturbations in the protein which were detected after only relatively short periods of exposure to silicone oil-water interfaces. Ad- ministration of OVA formulations that contained silicone oil microdroplets served to provoke the antibody response against OVA in mice. For proteins such as OVA that contain foreign epitopes, silicone oil can act as a potent immunological adjuvant. The level of response depends on the concentration of silicone oil microdroplets present in formulations and/or the amount of structurally perturbed protein adsorbed to the microdroplets. OVA formulations containing high concentrations of silicone oil microdroplets generated immune responses similar to those generated in response to alum-containing OVA formulations. Thus, in order to decrease the risk of an unwanted immune response to therapeutic protein products, it may be important to minimize the amount of silicone oil that can be injected into patients.

\section{ACKNOWLEDGMENTS}

Funding support for this study was provided by NIH grant ROI EB006006 and the FDA Office of Women's Health. This project was supported in part by an appointment to the ORISE Research Participation Program with the Center for Drug Evaluation and Research, US Food and Drug Administration, administered by the Oak Ridge Institute for Science and Education through an interagency agreement between the US Department of Energy and FDA/Center.

\section{REFERENCES}

1. Leader B, Baca QJ, Golan DE. 2008. Protein therapeutics: A summary and pharmacological classification. Nat Rev Drug Discov 7:21-39. 2. Sauerborn M, Brinks V, Jiskoot W, Schellekens H. 2010. Immunological mechanism underlying the immune response to recombinant human protein therapeutics. Trends Pharmacol Sci 31:53-59.

3. Shankar G, Pendley C, Stein KE. 2007. A risk-based bioanalytical strategy for the assessment of antibody immune responses against biological drugs. Nat Biotechnol 25:555-561.

4. De Groot AS, Scott DW. 2007. Immunogenicity of protein therapeutics. Trends Immunol 28:482-90.

5. Hoyer L. 1993. Factor VIII inhibitors: A continuing problem. J Lab Clin Med 121:385-387.

6. Macdougall IC. 2007. Epoetin-induced pure red cell aplasia: Diagnosis and treatment. Curr Opin Nephrol Hypertens 16:585-588.

7. Hermeling S, Crommelin DJA, Schellekens H, Jiskoot W. 2004. Structure-immunogenicity relationships of therapeutic proteins. Pharm Res 21:897-903.

8. Biro CE, Garcia G. 1965. The antigenicity of aggregated and aggregate-free human gamma-globulin for rabbits. Immunology 8:411419 .

9. Christian CL. 1960. Studies of aggregated gamma-globulin II. Effect in vivo. J Immunol 84:117-121.

10. Gamble CN. 1966. The role of soluble aggregates in the primary immune response of mice to human gamma globulin. Int Arch Allergy 30:446-455.

11. Ring J, Jesch F, Brendel W. 1977. Anaphylactoid reactions due to non-immune serum protein aggregates. Monogr Allergy 12:27-35.

12. Weksler ME, Bull G, Schwawrz GH, Stenzel KH, Rubin AL. 1970. Immunologic responses of graft recipients to antilymphocyte globulin: Effect of prior treatment with aggregate-free gamma globulin. J Clin Invest 49:1589-1595.

13. Fradkin AH, Carpenter JF, Randolph TW. 2009. Immunogenicity of aggregates of recombinant human growth hormone in mouse models. J Pharm Sci 98:3247-3264.

14. Joubert MK, Hokom M, Eakin C, Zhou L, Deshpande M, Baker MP, Goletz TJ, Kerwin BA, Chirmule N, Narhi LO, Jawa V. 2012. Highly 
aggregated antibody therapeutics can enhance the in vitro innate and late-stage T-cell immune responses. J Biol Chem 287:25266-25279.

15. Rombach-Riegraf V, Karle AC, Wolf B, Sordé L, Koepke S, Gottlieb S, Krieg J, Djidja M-C, Baban A, Spindeldreher S, Koulov AV, Kiessling A. 2014. Aggregation of human recombinant monoclonal antibodies influences the capacity of dendritic cells to stimulate adaptive T-cell responses in vitro. PLoS One 9:1-17.

16. Ahmadi M, Bryson CJ, Cloake EA, Welch K, Filipe V, Romeijn S, Hawe A, Jiskoot W, Baker MP, Fogg MH. 2015. Small amounts of subvisible aggregates enhance the immunogenic potential of monoclonal antibody therapeutics. Pharm Res 32:1383-1394.

17. Tyagi AK, Randolph TW, Dong A, Maloney KM, Jr Hitscherich C, Carpenter JF. 2009. IgG particle formation during filling pump operation: A case study of heterogeneous nucleation on stainless steel nanoparticles. J Pharm Sci 98:94-104.

18. U.S. Food and Drug Administration. 2011. Advisory to drug manufacturers: Formation of glass lamellae in certain injectable drugs. Accessed April 3, 2015, at: http://www.fda.gov/Drugs/DrugSafety/ ucm248490.htm.

19. Van Beers MMC, Gilli F, Schellekens H, Randolph TW, Jiskoot W. 2012. Immunogenicity of recombinant human interferon beta interacting with particles of glass, metal, and polystyrene. J Pharm Sci 101:187-199.

20. Fradkin AH, Carpenter JF, Randolph TW. 2011. Glass particles as an adjuvant: A model for adverse immunogenicity of therapeutic proteins. J Pharm Sci 100:4953-4964.

21. Shomali M, Freitag A, Engert J, Siedler M, Kaymakcalan Z, Winter G, Carpenter JF, Randolph TW. 2014. Antibody responses in mice to particles formed from adsorption of a murine monoclonal antibody onto glass microparticles. J Pharm Sci 103:78-89.

22. Romacker M, Schoenknecht T, Forster R. 2008. The rise of prefilled syringes from niche product to primary container of choice: A short history. Ondrug Deliv.4-5.

23. Jezek J, Darton NJ, Derham BK, Royle N, Simpson I. 2013. Biopharmaceutical formulations for pre-filled delivery devices. Expert Opin Drug Deliv 10:811-828.

24. Cleland J. 1993. The development of stable protein formulations: A close look at protein aggregation, deamidation, and oxidation. Crit Rev Ther Drug Carrier Syst 10:307-377.

25. Jenke DR. 2014. Extractables and leachables considerations for prefilled syringes. Expert Opin Drug Deliv 11:1591-1600.

26. Chantelau E, Berger M. 1985. Pollution of insulin with silicone oil, a hazard of disposable plastic syringes. Lancet 1:1459.

27. Chantelau E, Berger M, Bohlken B. 1986. Silicone oil released from disposable insulin syringes. Diabetes Care 9:672-673.

28. Bernstein R. 1987. Clouding and deactivation of clear (regular) human insulin: Association with silicone oil from disposable syringes? Diabetes Care 10:786-787.

29. Ludwig DB, Carpenter JF, Hamel J, Randolph TW. 2010. Protein adsorption and excipient effects on kinetic stability of silicone oil emulsions. J Pharm Sci 99:1721-1733.

30. Gerhardt A, Bonam K, Bee JS, Carpenter JF, Randolph TW. 2013. Ionic strength affects tertiary structure and aggregation propensity of a monoclonal antibody adsorbed to silicone oil-water interfaces. J Pharm Sci 102:429-440.

31. Britt KA, Schwartz DK, Wurth C, Mahler H, Carpenter JF, Randolph TW. 2012. Excipient effects on humanized monoclonal antibody interactions with silicone oil emulsions. J Pharm Sci 101:44194432 .

32. Thirumangalathu R, Krishnan S, Ricci MS, Brems DN, Randolph TW, Carpenter JF. 2009. Silicone oil- and agitation-induced aggregation of a monoclonal antibody in aqueous solution. J Pharm Sci 98:3167-3181.

33. Jones LS, Kaufmann A, Middaugh CR. 2005. Silicone oil induced aggregation of proteins. J Pharm Sci 94:918-27.

34. Gerhardt A, Mcgraw NR, Schwartz DK, Bee JS, Carpenter JF, Randolph TW. 2014. Protein aggregation and particle formation in prefilled glass syringes. J Pharm Sci 103:1601-1612.
35. Majumdar S, Ford BM, Mar KD, Sullivan VJ, Ulrich RG, D'souza AJM. 2011. Evaluation of the effect of syringe surfaces on protein formulations. J Pharm Sci 100:2563-2573.

36. Basu P, Krishnan S, Thirumangalathu R, Randolph TW, Carpenter JF. 2013. IgG1 aggregation and particle formation induced by siliconewater interfaces on siliconized borosilicate glass beads: A model for siliconized primary containers. J Pharm Sci 102:852-865.

37. Basu P, Blake-Haskins AW, O’Berry KB, Randolph TW, Carpenter JF. 2014. Albinterferon $\alpha 2 \mathrm{~b}$ adsorption to silicone oil-water interfaces: Effects on protein conformation, aggregation, and subvisible particle formation. J Pharm Sci 103:427-36.

38. Naim JO, Lanzafame RJ, Van Oss C. 1993. The adjuvant effect of silicone-gel on antibody formation in rats. Immunol Invest 22:151-161. 39. Shomali M, Tanriverdi S, Freitag AJ, Engert J, Winter G, Siedler M, Kaymakcalan Z, Carpenter JF, Randolph TW. 2015. Dose levels in particulate-containing formulations impact anti-drug antibody responses to murine monoclonal antibody in mice. J Pharm Sci 104:1610 1621.

40. Pretsch E, Bühlmann P, Affolter C. 2000. Structure determination of organic compounds: Tables of spectral data. 3rd ed. Berlin: SpringerVerlag.

41. Patton A, Mullenix MC, Swanson SJ, Koren E. 2005. An acid dissociation bridging ELISA for detection of antibodies directed against therapeutic proteins in the presence of antigen. J Immunol Methods 304:189-95.

42. Frey A, Di Canzio J, Zurakowski D. 1998. A statistically defined endpoint titer determination method for immunoassays. J Immunol Methods 221:35-41.

43. Malyala P, Singh M. 2008. Endotoxin limits in formulations for preclinical research. J Pharm Sci 97:2041-2044.

44. Rosenberg AS. 2006. Effects of protein aggregates: An immunologic perspective. AAPS J 8:E501-507.

45. Sacha GA, Saffell-clemmer W, Abram K, Akers MJ. 2010. Practical fundamentals of glass, rubber, and plastic sterile packaging systems. Pharm Dev Technol 15:6-34.

46. O'Hagan DT, De Gregorio E. 2009. The path to a successful vaccine adjuvant-The long and winding road. Drug Discov Today 14:541-551. 47. Eisenbarth SC, Colegio OR, O'Connor W, Sutterwala FS, Flavell RA. 2008. Crucial role for the Nalp3 inflammasome in the immunostimulatory properties of aluminium adjuvants. Nature 453:1122-1126. 48. Bungener L, Geeraedts F, Ter Veer W, Medema J, Wilschut J, Huckriede A. 2008. Alum boosts TH2-type antibody responses to wholeinactivated virus influenza vaccine in mice but does not confer superior protection. Vaccine 26:2350-2359.

49. HogenEsch H. 2002. Mechanisms of stimulation of the immune response by aluminum adjuvants. Vaccine 20:S34-S39.

50. Stevens T, Bossie A, Sanders V, Fernandez-Botran R, Coffman R, Mosmann T, Vitetta E. 1988. Regulation of antibody isotype secretion by subsets of antigen-specific helper T cells. Nature 334:255-258.

51. Schultze V, D’Agosto V, Wack A, Novicki D, Zorn J, Hennig R. 2008. Safety of MF59 adjuvant. Vaccine 26:3209-3222.

52. Singh M, Ugozzoli M, Kazzaz J, Chesko J, Soenawan E, Mannucci D, Titta F, Contorni M, Volpini G, Del Guidice G, O’Hagan DT. 2006. A preliminary evaluation of alternative adjuvants to alum using a range of established and new generation vaccine antigens. Vaccine 24:1680 1686.

53. Snapper CM, McIntyre T, Mandler R, Pecanha LMT, Finkelman FD, Lees A, Mond JJ. 1992. Induction of IgG3 secretion by interferon gamma: A model for T cell-independent class switching in response to T cell-independent type 2 antigens. J Exp Med 175:1367-1371.

54. Coutelier J, van der Logt JTM, Heessen FWA, Warnier G, van Snick J. 1987. IgG2a restriction of murine antibodies elicited by viral infections. J Exp Med 165:64-69.

55. Nimmerjahn F, Ravetch JV. 2005. Divergent immunoglobulin $\mathrm{g}$ subclass activity through selective Fc receptor binding. Science 310:1510-1512.

56. Murphy K, Travers P, Walport M. 2008. Janeway's immunobiology. 7th ed. New York: Garland Science. p 392-400. 